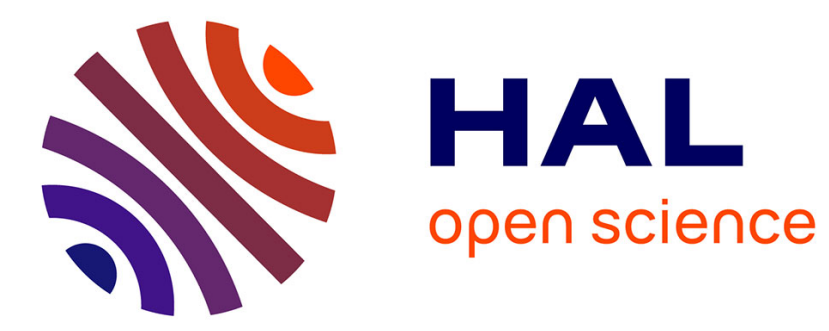

\title{
Lower Limb Mechanical Properties: Significant References Omitted
}

Jean-Benoît Morin, Olivier Girard, Jean Slawinski, Giuseppe Rabita, Georges Dalleau, Matt Brughelli

\section{- To cite this version:}

Jean-Benoît Morin, Olivier Girard, Jean Slawinski, Giuseppe Rabita, Georges Dalleau, et al.. Lower Limb Mechanical Properties: Significant References Omitted. Sports Medicine, 2012, 43 (2), pp.151153. 10.1007/s40279-012-0010-0 . hal-01232324

\section{HAL Id: hal-01232324 \\ https://hal.univ-reunion.fr/hal-01232324}

Submitted on 28 Oct 2016

HAL is a multi-disciplinary open access archive for the deposit and dissemination of scientific research documents, whether they are published or not. The documents may come from teaching and research institutions in France or abroad, or from public or private research centers.
L'archive ouverte pluridisciplinaire HAL, est destinée au dépôt et à la diffusion de documents scientifiques de niveau recherche, publiés ou non, émanant des établissements d'enseignement et de recherche français ou étrangers, des laboratoires publics ou privés. 


\title{
Lower Limb Mechanical Properties: Significant References Omitted
}

\author{
Jean-Benoit Morin - Olivier Girard · Jean Slawinski • \\ Giuseppe Rabita $\cdot$ Georges Dalleau $\cdot$ Matt Brughelli
}

We read with attention the recent narrative literature review by Pearson and McMahon [1]. We were very surprised and quite disappointed by the amount of relevant literature omitted by the authors on lower limb mechanical properties and, specifically, how 'limb stiffness' could affect performance and risk of injury. Although this review focuses on muscle-tendon unit (MTU) stiffness, the more global vertical, leg and joint stiffness (i.e. referred to as limb stiffness, collectively) are also reviewed, as the authors assume that limb stiffness is primarily controlled by MTU stiffness. Limb stiffness is used to describe the overall lower limb system as a "functional index of the changes in either center of mass or segment angle with the application of force" [1] in the well accepted 'spring-mass

\author{
J.-B. Morin $(\square)$ \\ Laboratory of Exercise Physiology (EA4338), \\ University of Lyon, Saint Etienne, France \\ e-mail: jean.benoit.morin@univ-st-etienne.fr \\ O. Girard \\ Research and Education Centre, Aspetar-Qatar Orthopaedic \\ and Sports Medicine Hospital, Doha, Qatar \\ J. Slawinski \\ Research Center on Sports and Movement (EA 2931), \\ University of Paris 10, Nanterre, France \\ G. Rabita \\ Research Department, French Institute of Sport (INSEP), \\ Paris, France \\ G. Dalleau \\ University of La Reunion, DIMPS-CURAPS (EA 4075), \\ Le Tampon, Réunion, France \\ M. Brughelli \\ Sports Performance Research Institute New Zealand, \\ AUT University, Auckland, New Zealand
}

model' [2-4]. Therefore, we did not understand the choice made by the authors to cite only some of the references obtainable $(n=73)$ using the search strategy they describe, although (i) they mention that "MEDLINE was utilized as the database for all articles found in the literature..." and (ii) the Sports Medicine instructions to authors stipulate that review articles should be "fully referenced, with all agents of relevance to the topic discussed in order to provide full coverage of the area". In our opinion, a review article is a unique opportunity for an exhaustive state of the art article and a sound basis for future research notably through the usual cross-reference and encyclopaedic process. We feel this opportunity has been missed and hereby list references omitted by the authors. The following references all appear through direct or simple cross-reference search strategies using the very same keywords as those listed by Pearson and McMahon [1]. Most of these references are published in high-ranked journals of the field 'sport sciences' [5], and even include review articles. For the sake of conciseness, we do not intend to provide an exhaustive list and, in order to be helpful to the reader, we list here some relevant references that would be worth appearing in various sections of Pearson and McMahon's paper [1].

In the introduction, a review paper [3] and two of the first papers to introduce the spring-mass model and the stiffness of the lower limb bouncing system during running and hopping $[2,6]$ would have helped the non-specialist reader better discover the concept. Other studies have made significant contributions to the overall understanding of 'leg' and 'vertical' stiffness e.g. [7-10].

In section 4, the authors point out that "Many previous studies have attempted to understand the relationship of stiffness to performance by examination of different tasks and how they correlate to stiffness" [1]. In addition to the 
studies they cite, we suggest considering the following studies about joint, vertical or leg stiffness during jumping [11], sprinting [12, 13] or repeated sprint running [14-16]. Research into how vertical or leg stiffness are altered with fatigue during or after short- (i.e. repeated sprint [14-17]), moderate- [18-21] or long-duration runs (i.e. several hours $[22,23])$ is undergoing unprecedented popularity. Additionally, the potential link with the energy cost of running $[24,25]$ is a crucial factor of human running performance [26]; for moderate intensity Heise and Martin found an inverse relationship between aerobic demand and stiffness [25]. For severe intensity, Dalleau et al. [24], Slawinski et al. [20], and Rabita et al. [19], confirmed that, during a constant-velocity, time-to-exhaustion run on track or treadmill, the same inverse relationship was observed. This inverse relationship was confirmed by a study showing that heavyweight training induced an improvement in running economy, most likely due to the associated increase in lower limb stiffness [27]. Finally, Morin et al. [28] could have been cited to further support the point that reducing ground contact time (thus increasing stride frequency) is also associated with increased leg stiffness in running. The amount of references mentioned in this paragraph clearly shows that evaluating and analysing stiffness through the spring-mass model is relevant for understanding the springlike leg behaviour in relation to human jumping, running and sprinting performance, in both fatigue and non-fatigue conditions.

In section 5, a series of studies addressing the effects of training on muscle and/or tendon mechanical properties (including stiffness) could have been mentioned [29-33]. In addition, other studies on MTU stiffness and performance could have been cited [34-38].

Section 6 discusses how stiffness might be considered a potential variable of interest for injury prevention. Butler et al. [39] published an interesting synthesis on this topic. Eiling et al. [40] demonstrated that menstrual-cycle hormones measured by estrogen levels influenced MTU stiffness, resulting in fluctuations of anterior knee joint laxity. Milner et al. [41, 42] reported that runners with a history of tibial stress fractures, a serious overuse injury, had higher sagittal plane knee stiffness than control subjects during running. Similarly, Hamill et al. [43] suggested that runners with lower back pain have higher knee joint stiffness compared with healthy runners. Lastly, several studies have considered leg stiffness as a potential factor in designing athletic footwear for injury prevention [44-46].

Section 7 dealing with "Lower limb stiffness determination and limitations to approaches" is probably the most under-referenced section. Here, the reader would certainly have benefited from references presenting reviews and critical analyses of existing methodologies [47-50], together with simple methods to calculate vertical and lower limb stiffness during jumping and running tasks [51, 52]. Although we acknowledge this very recent reference was likely not available to Pearson and McMahon at the time they wrote their review, the reader will benefit from being aware of the review by Serpell et al. [53].

Since all the references listed in the present letter appear directly in MEDLINE or after simple cross-referencing using title words or keywords such as 'leg stiffness', 'vertical stiffness', 'musculo-tendinous' or 'sprinting', as Pearson and McMahon mention, we are curious to understand the rationale these authors provide for not discussing such a substantial part of the recent literature in their review.

Acknowledgments All authors declare having no conflicts of interest that are directly relevant to the content of this letter

\section{References}

1. Pearson SJ, McMahon J. Lower limb mechanical properties: determining factors and implications for performance. Sports Med. 2012;42(11):929-40.

2. Blickhan R. The spring-mass model for running and hopping. J Biomech. 1989;22(11-12):1217-27.

3. Farley CT, Ferris DP. Biomechanics of walking and running: center of mass movements to muscle action. Exerc Sport Sci Rev. 1998;26(1):253-86.

4. McMahon TA, Cheng GC. The mechanics of running: how does stiffness couple with speed? J Biomech 1990;23(S1):65-78.

5. Hopkins WG. Impact factors of journals in sport and exercise science and medicine for 2011. Sportscience. 2011;15:15-7.

6. McMahon TA, Valiant G, Frederick EC. Groucho running. J Appl Physiol. 1987;62(6):2326-37.

7. Farley CT, Blickhan R, Saito J, et al. Hopping frequency in humans: a test of how springs set stride frequency in bouncing gaits. J Appl Physiol. 1991;71(6):2127-32.

8. Farley CT, Glasheen J, McMahon TA. Running springs: speed and animal size. J Exp Biol. 1993;185:71-86.

9. Geyer H, Seyfarth A, Blickhan R. Spring-mass running: simple approximate solution and application to gait stability. $\mathrm{J}$ Theor Biol. 2005;232(3):315-28.

10. Seyfarth A, Geyer H, Gunther M, et al. A movement criterion for running. J Biomech. 2002;35(5):649-55.

11. Laffaye G, Bardy BG, Durey A. Leg stiffness and expertise in men jumping. Med Sci Sports Exerc. 2005;37(4):536-43.

12. Kuitunen S, Komi PV, Kyrolainen H. Knee and ankle joint stiffness in sprint running. Med Sci Sports Exerc. 2002;34(1): 166-73.

13. Taylor MJ, Beneke R. Spring mass characteristics of the fastest men on earth. Int J Sports Med. 2012;33(8):667-70.

14. Girard O, Micallef JP, Millet GP. Changes in spring-mass model characteristics during repeated running sprints. Eur J Appl Physiol. 2011;111(1):125-34.

15. Girard O, Racinais S, Kelly L, et al. Repeated sprinting on natural grass impairs vertical stiffness but does not alter plantar loading in soccer players. Eur J Appl Physiol. 2011;111(10):2547-55.

16. Morin JB, Jeannin T, Chevallier B, et al. Spring-mass model characteristics during sprint running: correlation with performance and fatigue-induced changes. Int J Sports Med. 2006; 27(2):158-65. 
17. Morin JB, Tomazin K, Samozino P, et al. High-intensity sprint fatigue does not alter constant-submaximal velocity running mechanics and spring-mass behavior. Eur J Appl Physiol. 2011;112(4):1419-28.

18. Hunter I, Smith GA. Preferred and optimal stride frequency, stiffness and economy: changes with fatigue during a 1-h high intensity run. Eur J Appl Physiol. 2007;100:653-61.

19. Rabita G, Slawinski J, Girard O, et al. Spring-mass behavior during Exhaustive Run at Constant Velocity in Elite Triathletes. Med Sci Sports Exerc. 2011;43(4):685-92.

20. Slawinski J, Heubert R, Quievre J, Billat V, Hannon C. Changes in spring-mass model parameters and energy cost during track running to exhaustion. J Strength Cond Res. 2008;22(3):930-6.

21. Dutto DJ, Smith GA. Changes in spring-mass characteristics during treadmill running to exhaustion. Med Sci Sports Exerc. 2002;34(8):1324-31.

22. Morin JB, Samozino P, Millet GY. Changes in running kinematics, kinetics, and spring-mass behavior over a 24-h run. Med Sci Sports Exerc. 2011;43(5):829-36.

23. Morin JB, Tomazin K, Edouard P, Millet GY. Changes in running mechanics and spring-mass behavior induced by a mountain ultra-marathon race. J Biomech. 2011;44:1104-7.

24. Dalleau G, Belli A, Bourdin M, et al. The spring-mass model and the energy cost of treadmill running. Eur J Appl Physiol Occup Physiol. 1998;77(3):257-63.

25. Heise GD, Martin PE. "Leg spring" characteristics and the aerobic demand of running. Med Sci Sports Exerc. 1998;30(5): 750-4.

26. di Prampero PE, Atchou G, Bruckner JC, et al. The energetics of endurance running. Eur J Appl Physiol Occup Physiol. 1986; 55(3):259-66.

27. Millet GP, Jaouen B, Borrani F, et al. Effects of concurrent endurance and strength training on running economy and $\mathrm{VO}(2)$ kinetics. Med Sci Sports Exerc. 2002;34(8):1351-9.

28. Morin JB, Samozino P, Zameziati K, et al. Effects of altered stride frequency and contact time on leg-spring behavior in human running. J Biomech. 2007;40:3341-8.

29. Cornu C, Almeida Silveira MI, Goubel F. Influence of plyometric training on the mechanical impedance of the human ankle joint. Eur J Appl Physiol Occup Physiol. 1997; 76(3): 282-8.

30. Foure A, Nordez A, Cornu C. Plyometric training effects on Achilles tendon stiffness and dissipative properties. J Appl Physiol. 2010;109(3):849-54.

31. Foure A, Nordez A, Cornu C. Effects of plyometric training on passive stiffness of gastrocnemii muscles and Achilles tendon. Eur J Appl Physiol. 2012;112(8):2849-57.

32. Foure A, Nordez A, Guette M, et al. Effects of plyometric training on passive stiffness of gastrocnemii and the musculoarticular complex of the ankle joint. Scand J Med Sci Sports. 2009;19(6):811-8.

33. Foure A, Nordez A, McNair P, et al. Effects of plyometric training on both active and passive parts of the plantarflexors series elastic component stiffness of muscle-tendon complex. Eur J Appl Physiol. 2011;111(3):539-48.

34. Bojsen-Moller J, Magnusson SP, Rasmussen LR, et al. Muscle performance during maximal isometric and dynamic contractions is influenced by the stiffness of the tendinous structures. J Appl Physiol. 2005;99(3):986-94.
35. Kubo K, Morimoto M, Komuro T, et al. Influences of tendon stiffness, joint stiffness, and electromyographic activity on jump performances using single joint. Eur J Appl Physiol. 2007;99(3): 235-43.

36. Rabita G, Couturier A, Lambertz D. Intrinsic ankle and hopping leg-spring stiffness in distance runners and aerobic gymnasts. Int J Sports Med. 2011;32(7):552-8.

37. Spurrs RW, Murphy AJ, Watsford ML. The effect of plyometric training on distance running performance. Eur J Appl Physiol. 2003;89(1):1-7.

38. Walshe AD, Wilson GJ. The influence of musculotendinous stiffness on drop jump performance. Can J Appl Physiol. 1997; 22(2):117-32.

39. Butler RJ, Crowell HP, McClay Davis I. Lower extremity stiffness: implications for performance and injury. Clin Biomech. 2003; 18: 511-7.

40. Eiling E, Bryant AL, Petersen W, et al. Effects of menstrual-cycle hormone fluctuations on musculotendinous stiffness and knee joint laxity. Knee Surg Sports Traumatol Arthrosc. 2007;15(2): 126-32.

41. Milner CE, Ferber R, Pollard CD, et al. Biomechanical factors associated with tibial stress fracture in female runners. Med Sci Sports Exerc. 2006;38(2):323-8.

42. Milner CE, Hamill J, Davis I. Are knee mechanics during early stance related to tibial stress fracture in runners? Clin Biomech. 2007;22(6):697-703.

43. Hamill J, Moses M, Seay J. Lower extremity joint stiffness in runners with low back pain. Res Sports Med. 2009;17(4):260-73.

44. Bishop M, Fiolkowski P, Conrad B, et al. Athletic footwear, leg stiffness, and running kinematics. J Athl Train. 2006;41(4): 387-92.

45. Divert C, Baur H, Mornieux G, et al. Stiffness adaptations in shod running. J Appl Biomech. 2005;21:311-21.

46. Divert C, Mornieux G, Freychat P, et al. Barefoot-shod running differences: shoe or mass effect? Int J Sports Med. 2008;29(6): $512-8$.

47. Blum Y, Lipfert SW, Seyfarth A. Effective leg stiffness in running. J Biomech. 2009;42(14):2400-5.

48. Brughelli M, Cronin J. A review of research on the mechanical stiffness in running and jumping: methodology and implications. Scand J Med Sci Sports. 2008;18:417-26.

49. Brughelli M, Cronin J. Influence of running velocity on vertical, leg and joint stiffness : modelling and recommendations for future research. Sports Med. 2008;38(8):647-57.

50. Coleman DR, Cannavan D, Horne S, et al. Leg stiffness in human running: comparison of estimates derived from previously published models to direct kinematic-kinetic measures. J Biomech. 2012;45(11):1987-91.

51. Dalleau G, Belli A, Viale F, et al. A simple method for field measurements of leg stiffness in hopping. Int J Sports Med. 2004; 25(3):170-6.

52. Morin JB, Dalleau G, Kyrolainen H, et al. A simple method for measuring stiffness during running. J Appl Biomech. 2005;21(2): 167-80.

53. Serpell BG, Ball NB, Scarvell JM, et al. A review of models of vertical, leg, and knee stiffness in adults for running, jumping or hopping tasks. J Sports Sci. 2012;30(13):1347-63. 